\title{
Dynamical Analysis of a Nitrogen-Phosphorus-Phytoplankton Model
}

\author{
Yunli Deng, ${ }^{1,2}$ Min Zhao, ${ }^{2,3}$ Hengguo Yu, ${ }^{1,2}$ and Yi Wang ${ }^{1,2}$ \\ ${ }^{1}$ School of Mathematics and Information Science, Wenzhou University, Wenzhou, Zhejiang 325035, China \\ ${ }^{2}$ Zhejiang Provincial Key Laboratory for Water Environment and Marine Biological Resources Protection, \\ Wenzhou University, Wenzhou, Zhejiang 325035, China \\ ${ }^{3}$ School of Life and Environmental Sciences, Wenzhou University, Wenzhou, Zhejiang 325027, China \\ Correspondence should be addressed to Min Zhao; zmcn@tom.com
}

Received 7 October 2014; Accepted 23 November 2014

Academic Editor: Garyfalos Papashinopoulos

Copyright (C) 2015 Yunli Deng et al. This is an open access article distributed under the Creative Commons Attribution License, which permits unrestricted use, distribution, and reproduction in any medium, provided the original work is properly cited.

\begin{abstract}
This paper presents a nitrogen-phosphorus-phytoplankton model in a water ecosystem. The main aim of this research is to analyze the global system dynamics and to study the existence and stability of equilibria. It is shown that the phytoplankton-eradication equilibrium is globally asymptotically stable if the input nitrogen concentration is less than a certain threshold. However, the coexistence equilibrium is globally asymptotically stable as long as it exists. The system is uniformly persistent within threshold values of certain key parameters. Finally, to verify the results, numerical simulations are provided.
\end{abstract}

\section{Introduction}

In marine ecology, phytoplankton play a major role in nutrient cycling, primary production, and global carbon cycling. As is well known, nutrient validity is a necessary factor in phytoplankton population growth. However, the phytoplankton population will breed massively when nutrient input is excessive, eventually leading to eutrophication. Eutrophication can cause water-quality deterioration and fish killing and affect people's health and recreational activities [1]. It is characterized by frequently recurring algal blooms and reducing species diversity in water bodies at all trophic levels [2]. Therefore, reducing nutrients and eutrophication of water ecosystems is a crucial environmental problem throughout the world.

In 1932, Bertalanffy first proposed the use of mathematical models to study biological systems [3]. Then, some scientific researchers attempted to investigate the biological population dynamics use of mathematical models [4-6]. With the increasing prevalence of eutrophication and algae blooms, the history of mathematical modeling of plankton dynamics and biological eutrophication removal processes is already quite long and has been initiated by the biological sciences. Some approaches have been refined to provide more realistic descriptions of the development of biological natural populations. For instance, ecological models, including impulsive [7-9], diffusion [10, 11], and time delay [12-14], have been taken into account, which can explain certain phenomena in realistic world. In recent years, most efforts have focused on how to control eutrophication, how to predict algae outbreaks, and how to simulate algae spreading tendencies. In this context, many researchers have discussed the dynamic behavior of phytoplankton blooms [15-22]. Huppert et al. [23] presented a simple nutrient-phytoplankton model and explored the dynamics of phytoplankton blooms. Pei et al. [24] investigated a two-zooplankton and one-phytoplankton model with harvesting, which considered the impact of harvesting on the coexistence and competitive exclusion of competitive predators. Mukhopadhyay and Bhattacharyya [25] dealt with a nutrient-plankton model in an aquatic environment in the context of phytoplankton blooms. Zhang and Wang [26] considered a nutrient-phytoplankton-zooplankton model in an aquatic environment and analyzed its global dynamics. Fan et al. [27] proposed a new dynamic nutrient-plankton model and used it to study the relationship between nutritional enrichment and water-quality oscillations. However, researchers have 
paid little attention to modeling nitrogen-phosphorus-phytoplankton systems.

The Sanyang wetland of Wenzhou is located in a subtropical area and draws on the Wenzhou Economic Development zone and the Longwan zone to the east, linking up with the Chasan Higher Education zone to the south and connecting with the Wenzhou city center area to the northwest; its total area is 13 square kilometers. A certain number of rivers are distributed in a crosswise pattern, forming more than 160 different sizes and shapes of small islands; the proportion of land to water is $1.1: 1.47 \%$ of the land area is used to grow Mandarin oranges and $15.2 \%$ for housing, with the remainder used as agricultural land and fallow land. For the development of Wenzhou, the Sanyang wetland has played an important role in providing water resources, climate regulation, water conservation, flood and drought control, degradation of pollutants, and protection of biodiversity. However, the Sanyang wetland is facing the threat of industrial pollution and sewage, and its formerly crystal-clear water has become a large contaminated area, with local water areas colored red or black and emitting foul odors. Judging from the results of the overall analysis, the quality of the water environment in the Sanyang wetland has been severely damaged, with indicators of nitrogen, phosphorus, and heavy metals seriously exceeding limits. This situation has resulted in frequent nuisance algal blooms, which cause clogging and blocking of filtration systems. An even more frightening threat is that, with the economic development of Wenzhou city, the land and water bodies in the Sanyang wetland are in danger of being heavily invaded by industrial and building land uses as well as agricultural reclamation projects. Therefore, researching on how to enhance the protection of Sanyang wetland natural ecosystems and how to achieve a significant ecological effect on this environment is particularly important and urgent.

Nitrogen and phosphorus are necessary nutrient for plants to live. When small quantities of nutrients flow into a wetland, phytoplankton start to grow. If the process is allowed to proceed, blooms will break out. Laukkanen and Huhtala [1] stated that nitrogen and phosphorus are the primary factors limiting algae blooms, and therefore these two nutrients are considered in the present model. This paper presents a nitrogen-phosphorus-phytoplankton model and uses it to study the interaction between nutrient runoff and phytoplankton growth.

This paper considers a nitrogen-phosphorus-phytoplankton model with Holling type II functional response. The basic model is described by the following ordinary differential equations:

$$
\begin{aligned}
& \frac{d x}{d t}=I_{1}-b_{1} x-\frac{a_{1} x z}{c_{1}+x}, \\
& \frac{d y}{d t}=I_{2}-b_{2} y-\frac{a_{2} y z}{c_{2}+y}, \\
& \frac{d z}{d t}=\frac{e_{1} a_{1} x z}{c_{1}+x}+\frac{e_{2} a_{2} y z}{c_{2}+y}-m z,
\end{aligned}
$$

where $x$ and $y$ are, respectively, the density of total nitrogen $(\mathrm{mg} / \mathrm{L})$ and total phosphorus $(\mathrm{mg} / \mathrm{L})$ at time $t, z$ is the biomass of the phytoplankton population $(\mathrm{mg} / \mathrm{L})$ at time $t, I_{1}, I_{2}$ are, respectively, the runoff of nitrogen and phosphorus into the wetland, $b_{1}, b_{2}$ are, respectively, the natural removal of nitrogen and phosphorus from the water, $a_{1}, a_{2}$ are the maximum uptake rates, $e_{1}, e_{2}$ are biomass conversion constants, $m$ is the natural death rate of the phytoplankton population, $c_{1}, c_{2}$ are half-saturation constants, and the terms $a_{1} x z /\left(c_{1}+x\right)$ and $a_{2} y z /\left(c_{2}+y\right)$ represent the response function for nutrient uptake by phytoplankton. The system satisfies the following initial conditions: $x(0)=x_{0} \geq 0$, $y(0)=y_{0} \geq 0, z(0)=z_{0} \geq 0$.

This paper aims to obtain a theoretical result for which the values of the bifurcation parameter, the phytoplanktoneradication equilibrium point, and the coexistence equilibrium point are asymptotically stable. To verify the results, numerical simulation has been used to study the controlling relations on the bifurcation parameter $I_{1}$.

This paper is organized as follows. In the next section, the theorem governing the positivity and boundedness of solutions is analyzed. In Section 3, the conditions for existence and stability of equilibria are obtained. In Section 4, the uniform persistence of system (1) is examined. Finally, numerical simulations are described in Section 5, and discussion and conclusions are given in Section 6.

\section{Positivity and Boundedness of the Solution}

In this section, assuming the biologically meaningful initial conditions $x(0)=x_{0} \geq 0, y(0)=y_{0} \geq 0, z(0)=z_{0} \geq 0$, the theorem for the positivity and boundedness of system (1) is stated and proved.

Theorem 1. Under the given initial conditions, all solutions of system (1) are positive and uniformly bounded.

Proof. From the first equation of system (1),

$$
\frac{d x}{d t} \geq-b_{1} x-\frac{a_{1} x z}{c_{1}+x} .
$$

Hence, $x(t)>x(0) \exp \left[-\int_{0}^{t}\left(b_{1}+\left(a_{1} z /\left(c_{1}+x\right)\right)\right) d s\right]>0$.

Similarly, from the second equation of system (1),

$$
y(t)>y(0) \exp \left[-\int_{0}^{t}\left(b_{2}+\frac{a_{2} z}{c_{2}+y}\right) d s\right]>0 .
$$

From the third equation of system (1), it can be obtained that

$$
z(t)=z(0) \exp \left[\int_{0}^{t}\left(\frac{e_{1} a_{1} x}{c_{1}+x}+\frac{e_{2} a_{2} y}{c_{2}+y}-m\right) d s\right]>0 .
$$

Now let us define a Lyapunov function: $M(t)=e_{1} x+e_{2} y+z$. Let $d=\min \left\{b_{1}, b_{2}, m\right\}$.

Then,

$$
\frac{d M}{d t}+d M \leq e_{1} I_{1}+e_{2} I_{2}=L>0 .
$$


The right-hand side of the inequality is bounded for all $(x$, $y, z) \in R_{+}^{3}$, and therefore

$$
M(x, y, z)<\frac{L}{d}\left(1-e^{-d t}\right)+M(x(0), y(0), z(0)) e^{-d t} .
$$

Moreover, as $t \rightarrow+\infty, 0<M<L / d$. Hence, by the definition of $M(t)$, there are three positive constants $M_{x}, M_{y}$, and $M_{z}$ and $T_{1}>0$ such that $x(t) \leq M_{x}, y(t) \leq M_{y}, z(t) \leq$ $M_{z}$, for $t \geq T_{1}$. This completes the proof.

\section{Existence and Stability of Equilibria}

In this section, the existence of all possible nonnegative equilibria is first discussed.

Obviously, the phytoplankton-eradication equilibrium $E_{1}\left(I_{1} / b_{1}, I_{2} / b_{2}, 0\right)$ exists in system (1). Next, in order to research the coexistence of three populations, let us consider the existence of the positive equilibrium.

Theorem 2. There exists a coexistence equilibrium $E_{2}\left(x^{*}, y^{*}\right.$, $\left.z^{*}\right)$ of system (1) if

$$
0<m<\left(\frac{a_{1} e_{1} I_{1}}{\left(b_{1} c_{1}+I_{1}\right)}\right)+\left(\frac{a_{2} e_{2} I_{2}}{\left(b_{2} c_{2}+I_{2}\right)}\right) .
$$

Proof. If the coexistence equilibrium $E_{2}\left(x^{*}, y^{*}, z^{*}\right)$ exists, it must satisfy the following three equations:

$$
\begin{gathered}
I_{1}-b_{1} x^{*}-\frac{a_{1} x^{*} z^{*}}{c_{1}+x^{*}}=0, \\
I_{2}-b_{2} y^{*}-\frac{a_{2} y^{*} z^{*}}{c_{2}+y^{*}}=0, \\
\frac{e_{1} a_{1} x^{*}}{c_{1}+x^{*}}+\frac{e_{2} a_{2} y^{*}}{c_{2}+y^{*}}-m=0 .
\end{gathered}
$$

From (8), we must have $x^{*} \in\left(0, I_{1} / b_{1}\right)$ and $y^{*} \in\left(0, I_{2} / b_{2}\right)$ if the coexistence equilibrium exists.

From the first and the second equations of system (8), the following second degree equation in respect of $y^{*}$ is obtained:

$$
\begin{gathered}
a_{1} b_{2} x^{*} y^{* 2}+\left[a_{2}\left(I_{1}-b_{1} x^{*}\right)\left(c_{1}+x^{*}\right)-a_{1} x^{*}\left(I_{2}-b_{2} c_{2}\right)\right] y^{*} \\
-a_{1} I_{2} c_{2} x^{*}=0 .
\end{gathered}
$$

It is easy to calculate that

$$
\begin{aligned}
\Delta= & {\left[a_{2}\left(I_{1}-b_{1} x^{*}\right)\left(c_{1}+x^{*}\right)-a_{1} x^{*}\left(I_{2}-b_{2} c_{2}\right)\right]^{2} } \\
& +4 a_{1}^{2} b_{2} c_{2} I_{2} x^{* 2}>0 .
\end{aligned}
$$

Hence, there exist two roots in (9) $y_{1}$ and $y_{2}$, as follows:

$$
\begin{aligned}
& y_{1}=\frac{-f\left(x^{*}\right)+\sqrt{f^{2}\left(x^{*}\right)+4 a_{1}^{2} b_{2} c_{2} I_{2}}}{2 a_{1} b_{2}}, \\
& y_{2}=\frac{-f\left(x^{*}\right)-\sqrt{f^{2}\left(x^{*}\right)+4 a_{1}^{2} b_{2} c_{2} I_{2}}}{2 a_{1} b_{2}},
\end{aligned}
$$

where $f\left(x^{*}\right)=\left(a_{2}\left(I_{1}-b_{1} x^{*}\right)\left(c_{1}+x^{*}\right)-a_{1}\left(I_{2}-b_{2} c_{2}\right) x^{*}\right) / x^{*}$. Obviously, $y_{1}>0$ and $y_{2}<0$ in terms of expression (11). Thus, we just need to take into consideration $y_{1}$ because of $y^{*}>0$. Let $y_{1}=\varphi_{1}\left(x^{*}\right)$. Then,

$$
\varphi_{1}^{\prime}\left(x^{*}\right)=f^{\prime}\left(x^{*}\right) \frac{f\left(x^{*}\right)-\sqrt{f^{2}\left(x^{*}\right)+4 a_{1}^{2} b_{2} c_{2} I_{2}}}{2 a_{1} b_{2} \sqrt{f^{2}\left(x^{*}\right)+4 a_{1}^{2} b_{2} c_{2} I_{2}}} .
$$

Due to $f^{\prime}\left(x^{*}\right)=-a_{2}\left(\left(I_{1} c_{1} / x^{* 2}\right)+b_{1}\right)<0$, obviously, $\varphi_{1}^{\prime}\left(x^{*}\right)>0$. Therefore, $\varphi_{1}\left(x^{*}\right)$ is a strictly increasing and continuous function of $x^{*} \in\left(0, I_{1} / b_{1}\right)$. Moreover, $\lim _{x^{*} \rightarrow 0^{+}} \varphi_{1}\left(x^{*}\right)=0$. From (9), we have $y^{*}=0$ when $x^{*}=0$; thus, $y_{1}=\varphi_{1}\left(x^{*}\right)$ is continuous at the point $(0,0)$. In addition, $\varphi_{1}\left(I_{1} / b_{1}\right)=I_{2} / b_{2}$; hence, $\varphi_{1}\left(x^{*}\right)$ satisfy $(9)$ for $x^{*} \in\left[0, I_{1} / b_{1}\right]$.

From the third equation of system (8), it can be obtained that

$$
y^{*}=\frac{c_{2}\left(m-e_{1} a_{1}\right) x^{*}+m c_{1} c_{2}}{\left(e_{1} a_{1}+e_{2} a_{2}-m\right) x^{*}+c_{1}\left(e_{2} a_{2}-m\right)} \triangleq \varphi_{2}\left(x^{*}\right) .
$$

Because $\varphi_{2}^{\prime}\left(x^{*}\right)<0, \varphi_{2}\left(x^{*}\right)$ is a strictly decreasing and continuous function of $x^{*} \in\left(-\infty, c_{1}\left(m-e_{2} a_{2}\right) /\left(e_{1} a_{1}+e_{2} a_{2}-\right.\right.$ $m)) \cup\left(c_{1}\left(m-e_{2} a_{2}\right) /\left(e_{1} a_{1}+e_{2} a_{2}-m\right),+\infty\right)$.

Furthermore,

$$
\varphi_{2}(0)=\frac{m c_{2}}{e_{2} a_{2}-m}, \quad \varphi_{2}\left(\frac{m c_{1}}{e_{1} a_{1}-m}\right)=0 .
$$

The vertical asymptote is

$$
x^{*}=\frac{c_{1}\left(m-e_{2} a_{2}\right)}{e_{1} a_{1}+e_{2} a_{2}-m} .
$$

In addition,

$$
\lim _{x \rightarrow \infty} \varphi_{2}\left(x^{*}\right)=\frac{c_{2}\left(m-e_{1} a_{1}\right)}{e_{1} a_{1}+e_{2} a_{2}-m} .
$$

Based on the analysis of (14), (15), and (16), we know that $y^{*}=\varphi_{2}\left(x^{*}\right)$ and $y_{1}=\varphi_{1}\left(x^{*}\right)$ may intersect only if $x^{*} \epsilon$ $\left(c_{1}\left(m-e_{2} a_{2}\right) /\left(e_{1} a_{1}+e_{2} a_{2}-m\right),+\infty\right)$.

Let $\Psi\left(x^{*}, y^{*}\right)=y^{*}-\varphi_{2}\left(x^{*}\right)$, where $x^{*} \in\left(c_{1}(m-\right.$ $\left.\left.e_{2} a_{2}\right) /\left(e_{1} a_{1}+e_{2} a_{2}-m\right),+\infty\right)$. Because $\Psi(0,0)=-m<0$, when the condition $\Psi\left(I_{1} / b_{1}, I_{2} / b_{2}\right) \geq 0$ holds, then $\left\{\left(x^{*}, y^{*}\right) \mid y^{*}=\right.$ $\left.\varphi_{2}\left(x^{*}\right), x^{*} \in\left(c_{1}\left(m-e_{2} a_{2}\right) /\left(e_{1} a_{1}+e_{2} a_{2}-m\right),+\infty\right)\right\} \cap\left\{\left(x^{*}, y^{*}\right) \mid\right.$ $\left.y_{1}=\varphi_{1}\left(x^{*}\right), x^{*} \in\left[0, I_{1} / b_{1}\right]\right\} \neq \varnothing$. Whereas the condition $\Psi\left(I_{1} / b_{1}, I_{2} / b_{2}\right)=0$ is inconsistent with the coexistence equilibrium $E_{2}\left(x^{*}, y^{*}, z^{*}\right)$, the condition $\Psi\left(I_{1} / b_{1}, I_{2} / b_{2}\right)>0$ holds.

Obviously, $\Psi\left(I_{1} / b_{1}, I_{2} / b_{2}\right)>0$ if (7) holds. Thus, there must be unique $x^{*}, y^{*}$, and $z^{*}$ such that the expression (8) holds, because $\varphi_{1}\left(x^{*}\right)$ is a strictly increasing continuous function and $\varphi_{2}\left(x^{*}\right)$ is a strictly decreasing continuous function, where $y^{*}=\varphi_{2}\left(x^{*}\right), z^{*}=\left(I_{1}-b_{1} x^{*}\right)\left(c_{1}+x^{*}\right) /\left(a_{1} x^{*}\right)$, and $x^{*}$ is defined as the unique solution of $\varphi_{1}\left(x^{*}\right)=\varphi_{2}\left(x^{*}\right)$.

Therefore, when $0<m<\left(a_{1} e_{1} I_{1} /\left(b_{1} c_{1}+I_{1}\right)\right)+$ $\left(a_{2} e_{2} I_{2} /\left(b_{2} c_{2}+I_{2}\right)\right)$ holds, there exists a unique coexistence equilibrium $E_{2}\left(x^{*}, y^{*}, z^{*}\right)$ in system (1). The proof is complete. 
Next, the stability of the phytoplankton-eradication equilibrium $E_{1}\left(x_{1}, y_{1}, 0\right)$ will be discussed, where $x_{1}=I_{1} / b_{1}$ and $y_{1}=I_{2} / b_{2}$.

Theorem 3. The phytoplankton-eradication equilibrium $E_{1}\left(x_{1}, y_{1}, 0\right)$ is locally asymptotically stable if $m>\left(a_{1} e_{1} I_{1} /\right.$ $\left.\left(b_{1} c_{1}+I_{1}\right)\right)+\left(a_{2} e_{2} I_{2} /\left(b_{2} c_{2}+I_{2}\right)\right)$.

Proof. For $E_{1}\left(x_{1}, y_{1}, 0\right)$, the characteristic equation is

$$
\left(\begin{array}{ccc}
-b_{1}-\lambda & 0 & -\frac{a_{1} I_{1}}{b_{1} c_{1}+I_{1}} \\
0 & -b_{2}-\lambda & -\frac{a_{2} I_{2}}{b_{2} c_{2}+I_{2}} \\
0 & 0 & \frac{a_{1} e_{1} I_{1}}{b_{1} c_{1}+I_{1}}+\frac{a_{2} e_{2} I_{2}}{b_{2} c_{2}+I_{2}}-m-\lambda
\end{array}\right)=0 .
$$

The roots of the characteristics equation are

$$
\begin{aligned}
& \lambda_{1}=-b_{1}<0, \quad \lambda_{2}=-b_{2}<0, \\
& \lambda_{3}=\frac{a_{1} e_{1} I_{1}}{b_{1} c_{1}+I_{1}}+\frac{a_{2} e_{2} I_{2}}{b_{2} c_{2}+I_{2}}-m .
\end{aligned}
$$

It is easy to verify that $\lambda_{3}<0$ if $m>\left(a_{1} e_{1} I_{1} /\left(b_{1} c_{1}+I_{1}\right)\right)+$ $\left(a_{2} e_{2} I_{2} /\left(b_{2} c_{2}+I_{2}\right)\right)$.

Therefore, the phytoplankton-eradication equilibrium $E_{1}\left(x_{1}, y_{1}, 0\right)$ is locally asymptotically stable if $m>\left(a_{1} e_{1} I_{1} /\right.$ $\left.\left(b_{1} c_{1}+I_{1}\right)\right)+\left(a_{2} e_{2} I_{2} /\left(b_{2} c_{2}+I_{2}\right)\right)$. The proof is complete.

Theorem 4. The phytoplankton-eradication equilibrium $E_{1}\left(x_{1}, y_{1}, 0\right)$ is globally asymptotically stable if $m>\left(a_{1} e_{1} I_{1} /\right.$ $\left.\left(b_{1} c_{1}+I_{1}\right)\right)+\left(a_{2} e_{2} I_{2} /\left(b_{2} c_{2}+I_{2}\right)\right)$.

Proof. To investigate the global stability of system (1) at $E_{1}\left(x_{1}, y_{1}, 0\right)$, let us construct the following Lyapunov function:

$$
\begin{aligned}
V(x, y, z)= & w_{1} \int_{x_{1}}^{x} \frac{f(\xi)-f\left(x_{1}\right)}{f(\xi)} d \xi \\
& +w_{2} \int_{y_{1}}^{y} \frac{g(\xi)-g\left(y_{1}\right)}{g(\xi)} d \xi+w_{3} z,
\end{aligned}
$$

where $w_{1}, w_{2}, w_{3}$ are constants to be determined in subsequent steps and $f(x)=a_{1} x /\left(c_{1}+x\right), g(y)=a_{2} y /\left(c_{2}+y\right)$.

Along the trajectories of system (1),

$$
\begin{aligned}
\frac{d V}{d t}= & w_{1} \frac{f(x)-f\left(x_{1}\right)}{f(x)} \frac{d x}{d t}+w_{2} \frac{g(y)-g\left(y_{1}\right)}{g(y)} \frac{d y}{d t}+w_{3} \frac{d z}{d t} \\
= & -\frac{w_{1} b_{1}}{f(x)}\left(f(x)-f\left(x_{1}\right)\right)\left(x-x_{1}\right) \\
& -w_{1}\left(f(x)-f\left(x_{1}\right)\right) z
\end{aligned}
$$

$$
\begin{aligned}
& -\frac{w_{2} b_{2}}{g(y)}\left(g(y)-g\left(y_{1}\right)\right)\left(y-y_{1}\right) \\
& -w_{2}\left(g(y)-g\left(y_{1}\right)\right) z \\
& +w_{3}\left(e_{1} f(x) z+e_{2} g(y) z-m z\right) .
\end{aligned}
$$

Now, choosing $w_{1}=e_{1} w_{3}$ and $w_{2}=e_{2} w_{3}$,

$$
\begin{aligned}
\frac{d V}{d t}= & -\frac{e_{1} w_{3} b_{1}}{f(x)}\left(f(x)-f\left(x_{1}\right)\right)\left(x-x_{1}\right) \\
& -\frac{e_{2} w_{3} b_{2}}{g(y)}\left(g(y)-g\left(y_{1}\right)\right)\left(y-y_{1}\right) \\
& +w_{3}\left(e_{1} f\left(x_{1}\right)+e_{2} g\left(y_{1}\right)-m\right) z .
\end{aligned}
$$

Note that $f(x)$ and $g(y)$ are increasing functions and that the solution of (1) is positive. Meanwhile, it can be determined that $e_{1} f\left(x_{1}\right)+e_{2} g\left(y_{1}\right)-m<0$ is equal to $m>\left(a_{1} e_{1} I_{1} /\left(b_{1} c_{1}+\right.\right.$ $\left.\left.I_{1}\right)\right)+\left(a_{2} e_{2} I_{2} /\left(b_{2} c_{2}+I_{2}\right)\right)$. Therefore, each item on the righthand side of (21) is nonpositive; that is, $d V / d t \leq 0$ and $d V / d t=0$ if and only if $x=x_{1}, y=y_{1}$, and $z=0$. Based on the Lyapunov-LaSalle theorem, if $m>\left(a_{1} e_{1} I_{1} /\left(b_{1} c_{1}+\right.\right.$ $\left.\left.I_{1}\right)\right)+\left(a_{2} e_{2} I_{2} /\left(b_{2} c_{2}+I_{2}\right)\right)$, then the phytoplankton-eradication equilibrium $E_{1}\left(x_{1}, y_{1}, 0\right)$ is globally asymptotically stable. Hence, the proof is complete.

Finally, the stability of the coexistence equilibrium $E_{2}=$ $\left(x^{*}, y^{*}, z^{*}\right)$ will be discussed.

Theorem 5. The coexistence equilibrium $E_{2}=\left(x^{*}, y^{*}, z^{*}\right)$ is locally asymptotically stable if $0<m<\left(a_{1} e_{1} I_{1} /\left(b_{1} c_{1}+I_{1}\right)\right)+$ $\left(a_{2} e_{2} I_{2} /\left(b_{2} c_{2}+I_{2}\right)\right)$.

Proof. For $E_{2}=\left(x^{*}, y^{*}, z^{*}\right)$, the characteristic equation is

$$
\begin{aligned}
& \left(\begin{array}{ccc}
\lambda+b_{1}+\frac{a_{1} c_{1} z^{*}}{\left(c_{1}+x^{*}\right)^{2}} & 0 & \frac{a_{1} x^{*}}{c_{1}+x^{*}} \\
0 & \lambda+b_{2}+\frac{a_{2} c_{2} z^{*}}{\left(c_{2}+y^{*}\right)^{2}} & \frac{a_{2} y^{*}}{c_{2}+y^{*}} \\
-\frac{e_{1} a_{1} c_{1} z^{*}}{\left(c_{1}+x^{*}\right)^{2}} & -\frac{e_{2} a_{2} c_{2} z^{*}}{\left(c_{2}+y^{*}\right)^{2}} & \lambda
\end{array}\right) \\
& =0 \text {. }
\end{aligned}
$$

That is,

$$
\lambda^{3}+A_{1} \lambda^{2}+A_{2} \lambda+A_{3}=0
$$

where

$$
\begin{aligned}
A_{1}= & b_{1}+b_{2}+\frac{a_{1} c_{1} z^{*}}{\left(c_{1}+x^{*}\right)^{2}}+\frac{a_{2} c_{2} z^{*}}{\left(c_{2}+y^{*}\right)^{2}}>0, \\
A_{2}= & \left(b_{1}+\frac{a_{1} c_{1} z^{*}}{\left(c_{1}+x^{*}\right)^{2}}\right)\left(b_{2}+\frac{a_{2} c_{2} z^{*}}{\left(c_{2}+y^{*}\right)^{2}}\right) \\
& +\frac{a_{1}^{2} e_{1} c_{1} x^{*} z^{*}}{\left(c_{1}+x^{*}\right)^{3}}+\frac{a_{2}^{2} e_{2} c_{2} y^{*} z^{*}}{\left(c_{2}+y^{*}\right)^{3}}>0,
\end{aligned}
$$




$$
\begin{aligned}
A_{3}= & \frac{a_{1}^{2} e_{1} c_{1} x^{*} z^{*}}{\left(c_{1}+x^{*}\right)^{3}}\left(b_{2}+\frac{a_{2} c_{2} z^{*}}{\left(c_{2}+y^{*}\right)^{2}}\right) \\
& +\frac{a_{2}^{2} e_{2} c_{2} y^{*} z^{*}}{\left(c_{2}+y^{*}\right)^{3}}\left(b_{1}+\frac{a_{1} c_{1} z^{*}}{\left(c_{1}+x^{*}\right)^{2}}\right)>0 .
\end{aligned}
$$

Note that $A_{1}$ and $A_{3}$ are both positive. Based on the RouthHurwitz criterion, $E_{2}$ is locally asymptotically stable if and only if $A_{1} A_{2}-A_{3}>0$. In fact, after some computations,

$$
\begin{aligned}
A_{1} A_{2}-A_{3}= & \left(b_{1}+\frac{a_{1} c_{1} z^{*}}{\left(c_{1}+x^{*}\right)^{2}}\right)\left(b_{2}+\frac{a_{2} c_{2} z^{*}}{\left(c_{2}+y^{*}\right)^{2}}\right) \\
& \times\left[b_{1}+b_{2}+\frac{a_{1} c_{1} z^{*}}{\left(c_{1}+x^{*}\right)^{2}}+\frac{a_{2} c_{2} z^{*}}{\left(c_{2}+y^{*}\right)^{2}}\right] \\
& +\frac{a_{1}^{2} e_{1} c_{1} x^{*} z^{*}}{\left(c_{1}+x^{*}\right)^{3}}\left(b_{1}+\frac{a_{1} c_{1} z^{*}}{\left(c_{1}+x^{*}\right)^{2}}\right) \\
& +\frac{a_{2}^{2} e_{2} c_{2} y^{*} z^{*}}{\left(c_{2}+y^{*}\right)^{3}}\left(b_{2}+\frac{a_{2} c_{2} z^{*}}{\left(c_{2}+y^{*}\right)^{2}}\right)>0 .
\end{aligned}
$$

Hence, the coexistence equilibrium $E_{2}=\left(x^{*}, y^{*}, z^{*}\right)$ is locally asymptotically stable if $E_{2}$ exists. The proof is complete.

Theorem 6. The coexistence equilibrium $E_{2}=\left(x^{*}, y^{*}, z^{*}\right)$ is globally asymptotically stable if $0<m<\left(a_{1} e_{1} I_{1} /\left(b_{1} c_{1}+I_{1}\right)\right)+$ $\left(a_{2} e_{2} I_{2} /\left(b_{2} c_{2}+I_{2}\right)\right)$.

Proof. To investigate the global stability of system (1), at $E_{2}=$ $\left(x^{*}, y^{*}, z^{*}\right)$, let us construct the following Lyapunov function:

$$
\begin{aligned}
V(x, y, z)= & w_{1} \int_{x^{*}}^{x} \frac{f(\xi)-f\left(x^{*}\right)}{f(\xi)} d \xi \\
& +w_{2} \int_{y^{*}}^{y} \frac{g(\xi)-g\left(y^{*}\right)}{g(\xi)} d \xi+w_{3} \int_{z^{*}}^{z} \frac{\xi-z^{*}}{\xi} d \xi
\end{aligned}
$$

where $w_{1}, w_{2}, w_{3}$ are constants to be determined in subsequent steps and $f(x)=a_{1} x /\left(c_{1}+x\right), g(y)=a_{2} y /\left(c_{2}+y\right)$.

Along the trajectories of system (1),

$$
\begin{aligned}
\frac{d V}{d t}= & w_{1} \frac{f(x)-f\left(x^{*}\right)}{f(x)}\left[-b_{1}\left(x-x^{*}\right)+f\left(x^{*}\right) z^{*}-f(x) z\right] \\
& +w_{2} \frac{g(y)-g\left(y^{*}\right)}{g(y)} \\
& \times\left[-b_{2}\left(y-y^{*}\right)+g\left(y^{*}\right) z^{*}-g(y) z\right] \\
& +w_{3}\left(z-z^{*}\right) \\
& \times\left[e_{1}\left(f(x)-f\left(x^{*}\right)\right)+e_{2}\left(g(y)-g\left(y^{*}\right)\right)\right] .
\end{aligned}
$$

Because $f(x) z-f\left(x^{*}\right) z^{*}=\left(f(x)-f\left(x^{*}\right)\right) z^{*}+f(x)(z-$ $\left.z^{*}\right), g(y) z-g\left(y^{*}\right) z^{*}=\left(g(y)-g\left(y^{*}\right)\right) z^{*}+g(y)\left(z-z^{*}\right)$ and choosing $w_{1}=e_{1} w_{3}$ and $w_{2}=e_{2} w_{3}$, then

$$
\begin{aligned}
\frac{d V}{d t}= & -\frac{e_{1} w_{3} b_{1}}{f(x)}\left(f(x)-f\left(x^{*}\right)\right)\left(x-x^{*}\right) \\
& -\frac{e_{1} w_{3}}{f(x)}\left(f(x)-f\left(x^{*}\right)\right)^{2} z^{*} \\
& -\frac{e_{2} w_{3} b_{2}}{g(y)}\left(g(y)-g\left(y^{*}\right)\right)\left(y-y^{*}\right) \\
& -\frac{e_{2} w_{3}}{g(y)}\left(g(y)-g\left(y^{*}\right)\right)^{2} z^{*} .
\end{aligned}
$$

The proof of this is similar to the proof of the global asymptotical stability of $E_{1}$. It can be established that $d V / d t<$ 0 . Based on the Lyapunov-LaSalle theorem, the coexistence equilibrium $E_{2}=\left(x^{*}, y^{*}, z^{*}\right)$ is globally asymptotically stable if $E_{2}$ exists. Hence, the proof is complete.

\section{Uniform Persistence}

This section will discuss the uniform persistence of system (1). As discussed below, threshold expressions of some key parameters can be obtained under the condition of all-species persistence. The first step is to state the following lemma.

Lemma 7. If $a>0, b>0,(d x(t) / d t) \leq(\geq) b-a x(t)$, and $x(0)>0$, then $x(t) \leq(\geq)(b / a)+(x(0)-(b / a)) e^{-a t}$ for $t>0$.

Theorem 8. If $U>0$, then system (1) is uniformly persistent.

Proof. From Theorem 1, there are positive constants $M_{x}, M_{y}$, and $M_{z}$ and $T_{1}>0$ such that $x(t) \leq M_{x}, y(t) \leq M_{y}, z(t) \leq$ $M_{z}$ for $t \geq T_{1}$.

On the other hand, from the first equation of system (1), it can be determined that

$$
\frac{d x(t)}{d t} \geq I_{1}-\left(b_{1}+\frac{a_{1} M_{z}}{c_{1}}\right) x .
$$

Noting that Lemma 7 is satisfied, then

$$
\begin{aligned}
x(t) \geq & \frac{I_{1} c_{1}}{b_{1} c_{1}+a_{1} M_{z}} \\
& +\left(x(0)-\frac{I_{1} c_{1}}{b_{1} c_{1}+a_{1} M_{z}}\right) e^{-\left(b_{1}+\left(a_{1} M_{z} / c_{1}\right)\right) t} \quad \text { for } t>0 .
\end{aligned}
$$

Therefore, there are positive constants $T_{2}, \varepsilon_{1}$, and $m_{x}$ such that

$$
x(t) \geq\left(\frac{I_{1} c_{1}}{\left(b_{1} c_{1}+a_{1} M_{z}\right)}\right)-\varepsilon_{1}=m_{x} \text { for } t \geq T_{2} .
$$

From the second equation of system (1), it follows that $(d y(t) / d t) \geq I_{2}-\left(b_{2}+\left(a_{2} M_{z} / c_{2}\right)\right) y$. Therefore, there are positive constants $T_{3}, \varepsilon_{2}$, and $m_{y}$ such that $y(t) \geq\left(I_{2} c_{2} /\left(b_{2} c_{2}+\right.\right.$ $\left.\left.a_{2} M_{z}\right)\right)-\varepsilon_{2}=m_{y}$ for $t \geq T_{3}$. 
TABLE 1: Parameter values of system (1).

\begin{tabular}{lcc}
\hline Symbol & Value & Units \\
\hline$a_{1}$ & 0.4 & day $^{-1}$ \\
$a_{2}$ & 0.5 & day $^{-1}$ \\
$b_{1}$ & 0.4 & day $^{-1}$ \\
$b_{2}$ & 0.5 & day $^{-1}$ \\
$c_{1}$ & 2 & $\mathrm{mg} / \mathrm{L}$ \\
$c_{2}$ & 3 & $\mathrm{mg} / \mathrm{L}$ \\
$e_{1}$ & 0.6 & Dimensionless \\
$e_{2}$ & 0.5 & Dimensionless \\
$m$ & 0.1 & day \\
$I_{2}$ & 0.3 & $\mathrm{mg} / \mathrm{L}$ \\
\hline
\end{tabular}

From the third equation of system (1), it follows that $(d z(t) / d t) \geq\left(\left(e_{1} a_{1} m_{x} /\left(c_{1}+M_{x}\right)\right)+\left(e_{2} a_{2} m_{y} /\left(c_{2}+M_{y}\right)\right)-m\right) z$. Therefore, it is evident that if $U=\left(e_{1} a_{1} m_{x} /\left(c_{1}+M_{x}\right)\right)+$ $\left(e_{2} a_{2} m_{y} /\left(c_{2}+M_{y}\right)\right)-m>0$, there are two positive constants $T_{4}$ and $m_{z}$ such that $z(t) \geq m_{z}$ for $t \geq T_{4}$.

Let $T=\max \left\{T_{1}, T_{2}, T_{3}, T_{4}\right\}$; then, it can be obtained that $m_{x} \leq x(t) \leq M_{x}, m_{y} \leq y(t) \leq M_{y}$, and $m_{z} \leq z(t) \leq M_{z}$ for $t \geq T$. Hence, the proof is complete.

\section{Simulation Analysis and Results}

The stability of the phytoplankton-eradication equilibrium point and the coexistence equilibrium point of system (1) has been demonstrated in the previous section. In this section, numerical simulations will be used to analyze the dynamic behavior of system (1). $I_{1}$ is chosen as the bifurcation parameter. Table 1 provides the values of the other fixed parameters and their units, which have been obtained from previous studies [27-29].

Based on the previous analysis, we know that a unique coexistence equilibrium exists in system (1) if $0<m<$ $\left(a_{1} e_{1} I_{1} /\left(b_{1} c_{1}+I_{1}\right)\right)+\left(a_{2} e_{2} I_{2} /\left(b_{2} c_{2}+I_{2}\right)\right)$. According to the parameter values in Table 1 , it is easy to compute that

$$
\left(\frac{a_{1} e_{1} I_{1}}{\left(b_{1} c_{1}+I_{1}\right)}\right)+\left(\frac{a_{2} e_{2} I_{2}}{\left(b_{2} c_{2}+I_{2}\right)}\right) \approx 0.12 \text {. }
$$

From Figure 1, it is easy to see that the curves $y=\varphi_{2}(x)$ and $y=\varphi_{1}(x)$ intersect when $m=0.05$ and 0.1 , while, if $m=0.15$ and 0.2 , the curves $y=\varphi_{2}(x)$ and $y=\varphi_{1}(x)$ do not intersect which is shown in Figure 1. Therefore, Figure 1 verifies the correctness of the theoretical results.

From Theorem 3, the phytoplankton-eradication equilibrium $E_{1}$ is locally asymptotically stable if

$$
m>\left(\frac{a_{1} e_{1} I_{1}}{\left(b_{1} c_{1}+I_{1}\right)}\right)+\left(\frac{a_{2} e_{2} I_{2}}{\left(b_{2} c_{2}+I_{2}\right)}\right) .
$$

Therefore, a condition has been obtained which is equivalent to inequality (33):

$$
I_{1}<\left(\frac{a_{1} b_{1} c_{1} e_{1}\left(b_{2} c_{2}+I_{2}\right)}{\left(\left(a_{1} e_{1}-m\right)\left(b_{2} c_{2}+I_{2}\right)+a_{2} e_{2} I_{2}\right)}\right)-b_{1} c_{1} .
$$

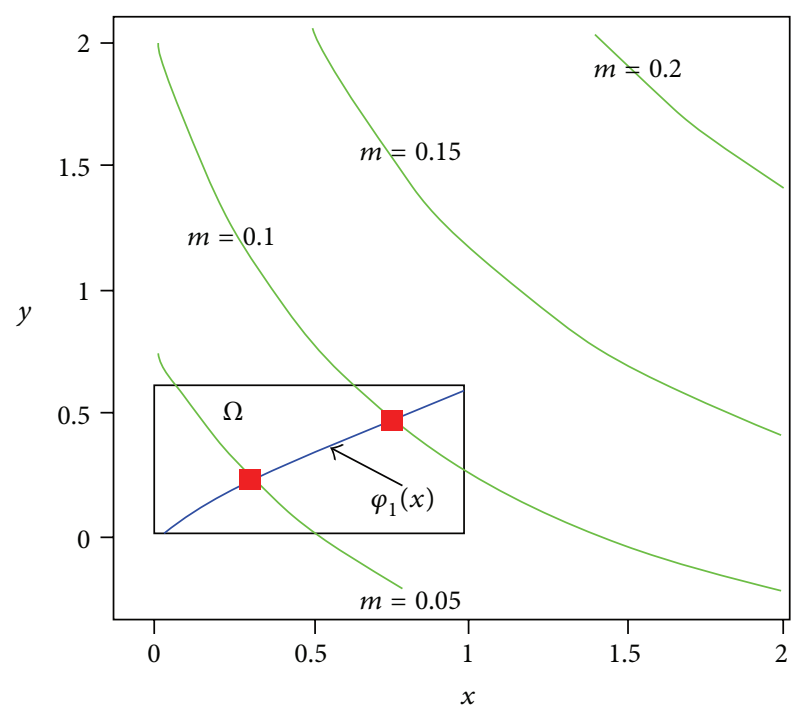

FIgURE 1: The illustration on the existence of the coexistence equilibrium. The gray closed area denotes the region $\Omega=\left[0, I_{1} / b_{1}\right] \times$ $\left[0, I_{2} / b_{2}\right]$, the blue curve denotes the curve $y=\varphi_{1}(x)$, the green curves represent the curves $y=\varphi_{2}(x)$ with the change of $m, m=$ $0.05, m=0.1, m=0.15$, and $m=0.2$, and the red diamond implies the crossover point of $y=\varphi_{2}(x)$ and $y=\varphi_{1}(x)$, where $I_{1}=0.4$ and the other parameters are the same as in Table 1.

Based on the parameter values in Table 1, it is easy to obtain that

$$
\left(\frac{a_{1} b_{1} c_{1} e_{1}\left(b_{2} c_{2}+I_{2}\right)}{\left(\left(a_{1} e_{1}-m\right)\left(b_{2} c_{2}+I_{2}\right)+a_{2} e_{2} I_{2}\right)}\right)-b_{1} c_{1} \approx 0.2569 \text {. }
$$

It can be determined that $E_{1}(0.25,0.6,0)$ is locally asymptotically stable if the input nitrogen concentration is $0.1 \mathrm{mg} / \mathrm{L}$, as shown in Figure 2(a). Therefore, the conditions of Theorem 3 are satisfied. When the input nitrogen concentration reaches $0.3 \mathrm{mg} / \mathrm{L}, E_{2}(0.68,0.56,0.28)$ exists and is locally asymptotically stable, as shown in Figure 2(b). Therefore, the conditions of Theorem 5 are satisfied.

In addition, Figure 3 shows the bifurcation diagram in the $I_{1}-z$ plane. This figure shows the dynamic behavior of system (1) for increasing input nitrogen concentration. A threshold for input nitrogen concentration can be seen to exist. When $I_{1}$ is less than this threshold, that is, $I_{1}<0.2569 \mathrm{mg} / \mathrm{L}$, only $E_{1}$ exists, and $E_{1}$ is globally asymptotically stable. When $I_{1}$ is greater than this threshold, that is, $I_{1}>0.2569 \mathrm{mg} / \mathrm{L}, E_{1}$ and $E_{2}$ exist, but $E_{1}$ is unstable and $E_{2}$ is globally asymptotically stable. These simulation results are in line with Theorems 4 and 6. Therefore, it is possible to speculate that $E_{2}$ is globally asymptotically stable if and only if $E_{1}$ is unstable.

\section{Discussion}

This paper has discussed the nitrogen-phosphorus-phytoplankton model. The model is simple because it assumes that phytoplankton is not affected by other environmental factors. The model is only an abstraction of real ecological phenomena; however, it generates many characteristics of 


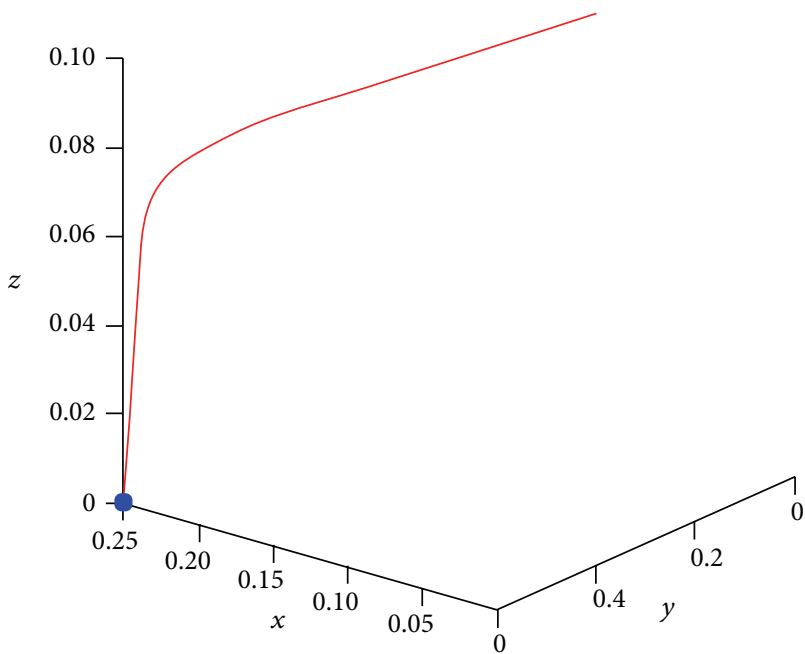

(a)

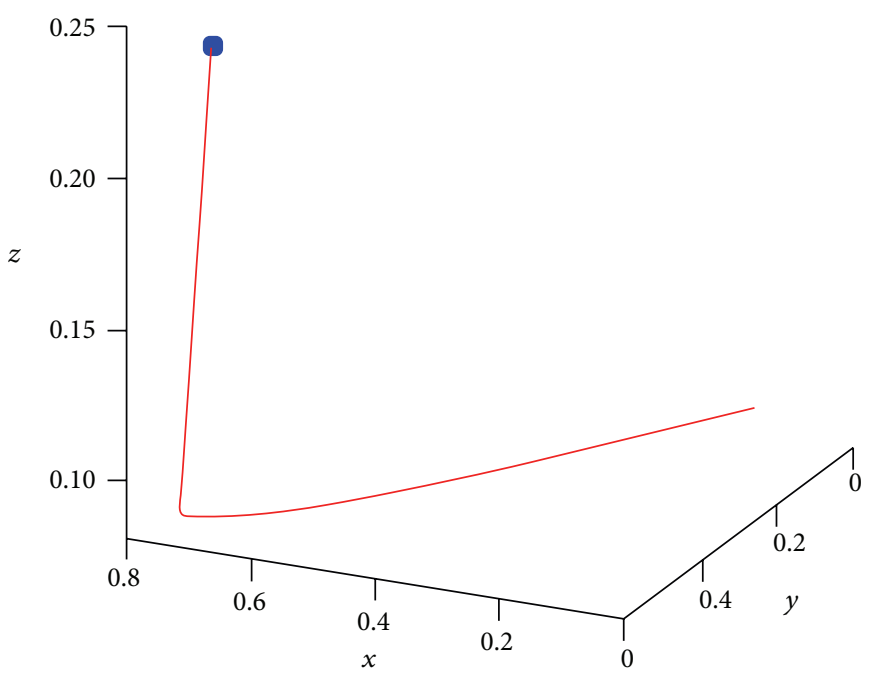

(b)

FIgURE 2: Phase diagram of system (1) under initial conditions $(x(0), y(0), z(0))=(0.1,0.1,0.1)$. (a) shows that $E_{1}(0.25,0.6,0)$ is locally asymptotically stable if $I_{1}=0.1 \mathrm{mg} / \mathrm{L}$; (b) shows that $E_{2}(0.68,0.56,0.28)$ exists and that $E_{2}$ is locally asymptotically stable if $I_{1}=0.3 \mathrm{mg} / \mathrm{L}$. The other parameters are the same as in Table 1.

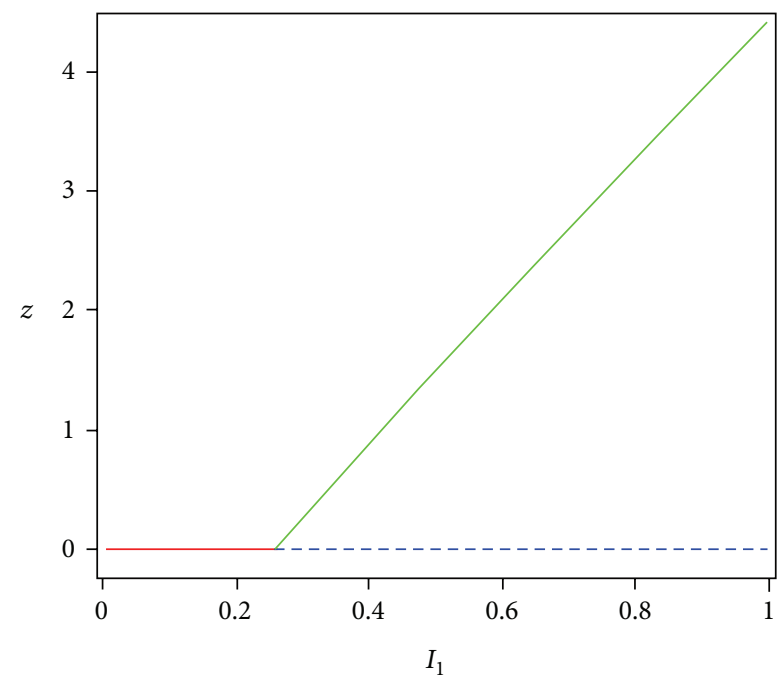

FIGURE 3: Bifurcation diagram of phytoplankton population with increasing input nitrogen concentration. The other parameters are the same as in Table 1 . The red solid line indicates that $E_{1}$ exists and is globally asymptotically stable. The blue dashed line implies that $E_{1}$ exists, but is unstable. The green solid line indicates that $E_{2}$ exists and is globally asymptotically stable.

these phenomena. Certain conditions for boundedness of solutions and existence and stability of equilibria have been obtained. Global stability of the system has been proved by constructing the Lyapunov function. Furthermore, the uniform persistence of the system has been analyzed.

According to the theoretical analysis and numerical simulation results, the concentrations of input nitrogen and phosphorus are an important factor in the system dynamics.
Using the input nitrogen concentration $I_{1}$ as a bifurcation parameter, the relationship between phytoplankton and nitrogen input has been examined. Figures 2 and 3 show that if $I_{1}$ is less than a certain threshold, $E_{1}$ is globally asymptotically stable; when $I_{1}$ is greater than this threshold, $E_{1}$ is unstable and $E_{2}$ is globally asymptotically stable. Hence, it can be conjectured that $E_{2}$ is globally asymptotically stable if and only if $E_{1}$ is unstable. All these results are expected to be of significance in the study of dynamic ecosystem complexity.

\section{Conflict of Interests}

The authors declare that there is no conflict of interests regarding the publication of this paper.

\section{Acknowledgments}

This work was supported by the National Natural Science Foundation of China (Grant no. 31370381), the Key Program of Zhejiang Provincial Natural Science Foundation of China (Grant no. LZ12C03001), the National Key Basic Research Program of China (973 Program, Grant no. 2012CB426510), and the Zhejiang Provincial Natural Science Foundation of China (Grant no. LY13A010010).

\section{References}

[1] M. Laukkanen and A. Huhtala, "Optimal management of a eutrophied coastal ecosystem: balancing agricultural and municipal abatement measures," Environmental and Resource Economics, vol. 39, no. 2, pp. 139-159, 2008.

[2] B. Q. Qin, "Lake eutrophication: control countermeasures and recycling exploitation," Ecological Engineering, vol. 35, no. 11, pp. 1569-1573, 2009. 
[3] L. V. Bertalanffy, Theoretische Biologie, Gebrüder Borntraeger, Berlin, Germany, 1932.

[4] M. Zhao, H. Yu, and J. Zhu, "Effects of a population floor on the persistence of chaos in a mutual interference host-parasitoid model," Chaos, Solitons and Fractals, vol. 42, no. 2, pp. 12451250, 2009.

[5] A. Dube and G. Jayaraman, "Mathematical modelling of the seasonal variability of plankton in a shallow lagoon," Nonlinear Analysis: Theory, Methods and Applications, vol. 69, no. 3, pp. 850-865, 2008.

[6] S. A. Gourley and S. Ruan, "Spatio-temporal delays in a nutrient-plankton model on a finite domain: linear stability and bifurcations," Applied Mathematics and Computation, vol. 145, no. 2-3, pp. 391-412, 2003.

[7] C. J. Dai, M. Zhao, and L. S. Chen, "Dynamic complexity of an Ivlev-type prey-predator system with impulsive state feedback control," Journal of Applied Mathematics, vol. 2012, Article ID 534276, 17 pages, 2012.

[8] L. F. Nie, Z. D. Teng, L. Hu, and J. G. Peng, "Existence and stability of periodic solution of a predator-prey model with state-dependent impulsive effects," Mathematics and Computers in Simulation, vol. 79, no. 7, pp. 2122-2134, 2009.

[9] G. Jiang and Q. Lu, "Impulsive state feedback control of a predator-prey model," Journal of Computational and Applied Mathematics, vol. 200, no. 1, pp. 193-207, 2007.

[10] Y. Tian and P. Weng, "Stability analysis of diffusive predatorprey model with modified Leslie-Gower and Holling-type III schemes," Applied Mathematics and Computation, vol. 218, no. 7, pp. 3733-3745, 2011

[11] Z. Yue and W. Wang, "Qualitative analysis of a diffusive ratiodependent Holling-Tanner predator-prey model with Smith growth," Discrete Dynamics in Nature and Society, vol. 2013, Article ID 267173, 9 pages, 2013.

[12] X. Z. Meng, J. J. Jiao, and L. S. Chen, "The dynamics of an age structured predator-prey model with disturbing pulse and time delays," Nonlinear Analysis: Real World Applications, vol. 9, no. 2, pp. 547-561, 2008.

[13] H. Yu, M. Zhao, and R. P. Agarwal, "Stability and dynamics analysis of time delayed eutrophication ecological model based upon the Zeya reservoir," Mathematics and Computers in Simulation, vol. 97, pp. 53-67, 2014.

[14] D. Wu, H. Zhang, J. Cao, and T. Hayat, "Stability and bifurcation analysis of a nonlinear discrete logistic model with delay," Discrete Dynamics in Nature and Society, vol. 2013, Article ID 463059, 7 pages, 2013.

[15] J. H. Luo, "Phytoplankton-zooplankton dynamics in periodic environments taking into account eutrophication," Mathematical Biosciences, vol. 245, no. 2, pp. 126-136, 2013.

[16] S. R. Jang, "Dynamics of variable-yield nutrient-phytoplanktonzooplankton models with nutrient recycling and self-shading," Journal of Mathematical Biology, vol. 40, no. 3, pp. 229-250, 2000.

[17] L. J. Alvarez-Vázquez, F. J. Fernández, and R. Muñoz-Sola, "Mathematical analysis of a three-dimensional eutrophication model," Journal of Mathematical Analysis and Applications, vol. 349, no. 1, pp. 135-155, 2009.

[18] K. Chakraborty, S. Jana, and T. K. Kar, "Global dynamics and bifurcation in a stage structured prey-predator fishery model with harvesting," Applied Mathematics and Computation, vol. 218, no. 18, pp. 9271-9290, 2012.
[19] Y. Wang, M. Zhao, C. Dai, and X. Pan, "Nonlinear dynamics of a nutrient-plankton model," Abstract and Applied Analysis, vol. 2014, Article ID 451757, 10 pages, 2014.

[20] M. Gao, H. Shi, and Z. Li, "Chaos in a seasonally and periodically forced phytoplankton-zooplankton system," Nonlinear Analysis: Real World Applications, vol. 10, no. 3, pp. 1643-1650, 2009.

[21] J. Zhao and J. Wei, "Stability and bifurcation in a two harmful phytoplankton-zooplankton system," Chaos, Solitons and Fractals, vol. 39, no. 3, pp. 1395-1409, 2009.

[22] H. Yu, M. Zhao, and Q. Wang, "Analysis of mathematics and sustainability in an impulsive eutrophication controlling system," Abstract and Applied Analysis, vol. 2013, Article ID 726172, 13 pages, 2013.

[23] A. Huppert, R. Olinky, and L. Stone, "Bottom-up excitable models of phytoplankton blooms," Bulletin of Mathematical Biology, vol. 66, no. 4, pp. 865-878, 2004.

[24] Y. Pei, Y. Lv, and C. Li, "Evolutionary consequences of harvesting for a two-zooplankton one-phytoplankton system," Applied Mathematical Modelling, vol. 36, no. 4, pp. 1752-1765, 2012.

[25] B. Mukhopadhyay and R. Bhattacharyya, "Modelling phytoplankton allelopathy in a nutrient-plankton model with spatial heterogeneity," Ecological Modelling, vol. 198, no. 1-2, pp. 163173, 2006.

[26] T. Zhang and W. Wang, "Hopf bifurcation and bistability of a nutrient-phytoplankton-zooplankton model," Applied Mathematical Modelling, vol. 36, no. 12, pp. 6225-6235, 2012.

[27] A. Fan, P. Han, and K. Wang, "Global dynamics of a nutrientplankton system in the water ecosystem," Applied Mathematics and Computation, vol. 219, no. 15, pp. 8269-8276, 2013.

[28] K.-G. Mäler, "Development, ecological resources and their management: a study of complex dynamic systems," European Economic Review, vol. 44, no. 4-6, pp. 645-665, 2000.

[29] A. M. Edwards, "Adding detritus to a nutrient-phytoplanktonzooplankton model: a dynamical-systems approach," Journal of Plankton Research, vol. 23, no. 4, pp. 389-413, 2001. 


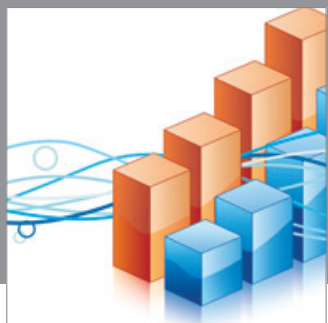

Advances in

Operations Research

mansans

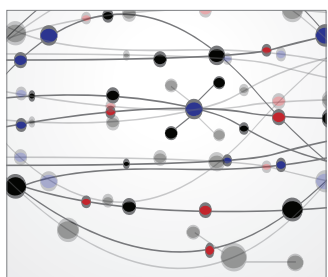

The Scientific World Journal
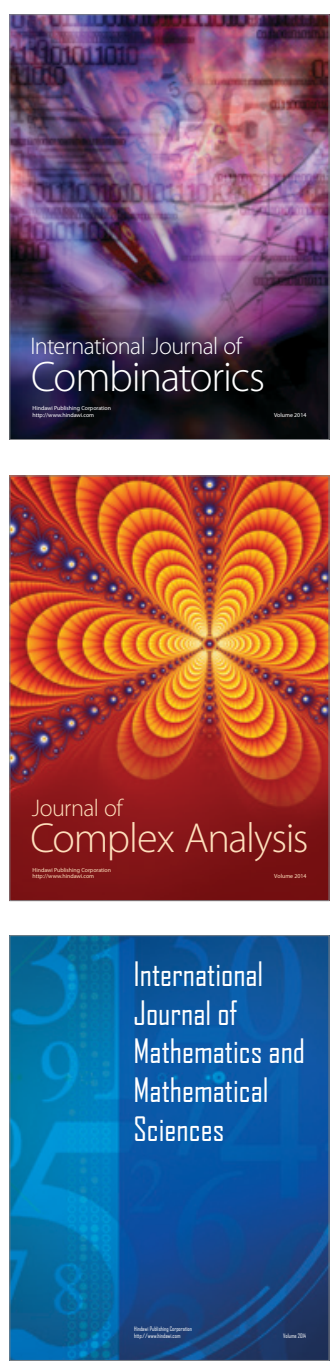
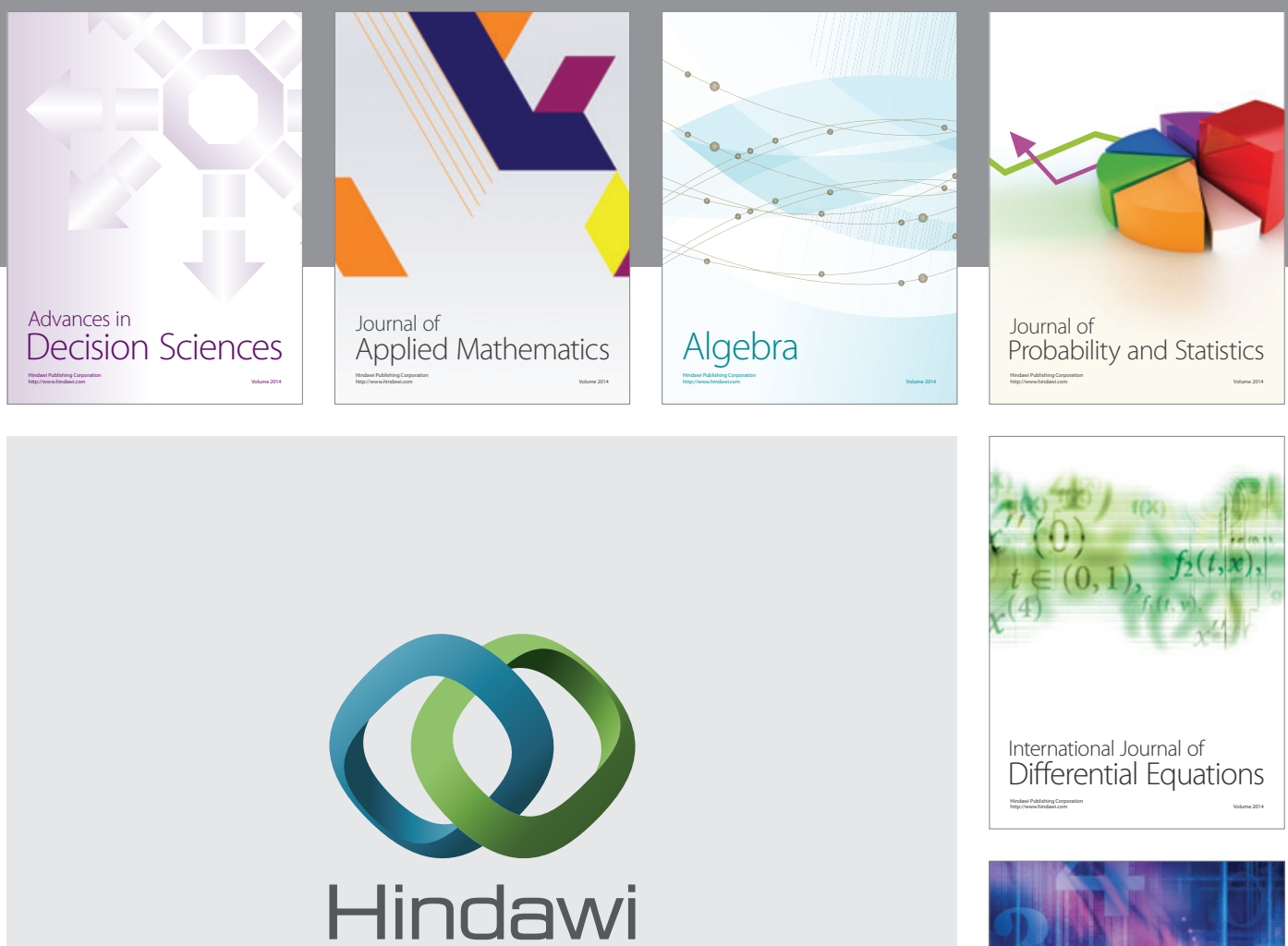

Submit your manuscripts at http://www.hindawi.com
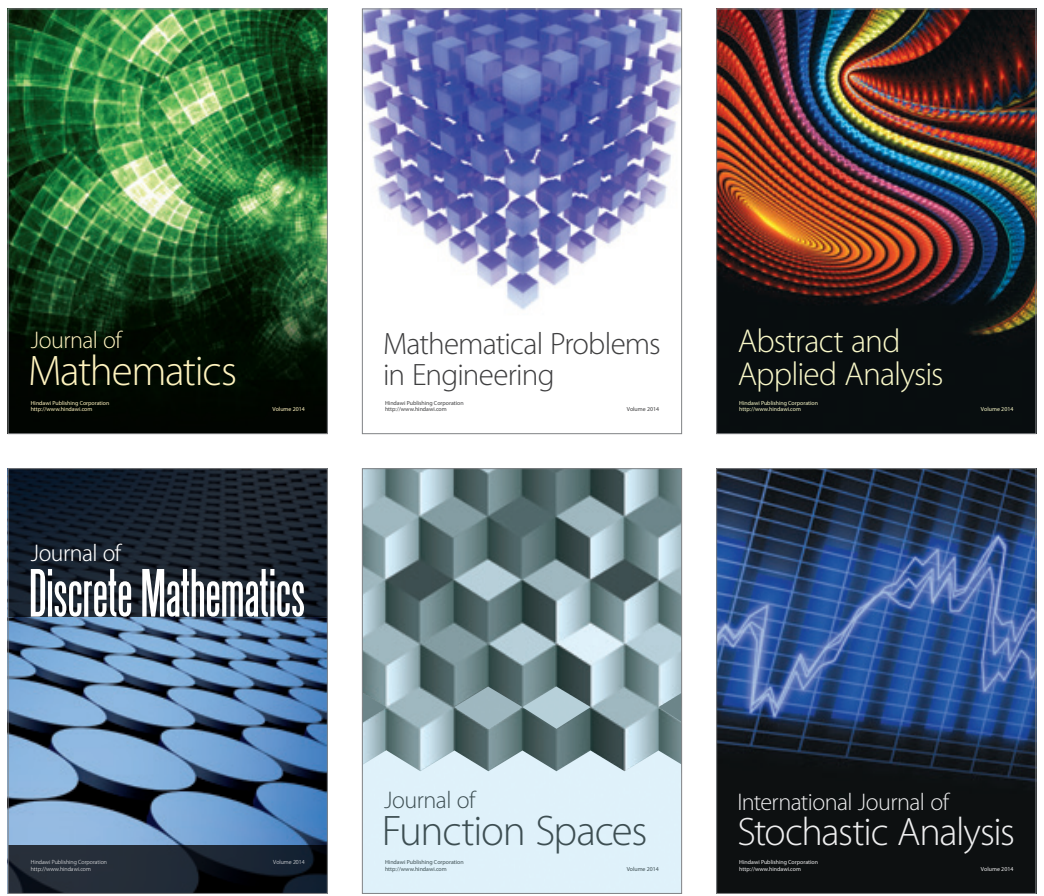

Journal of

Function Spaces

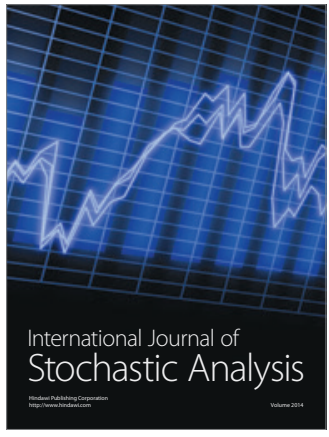

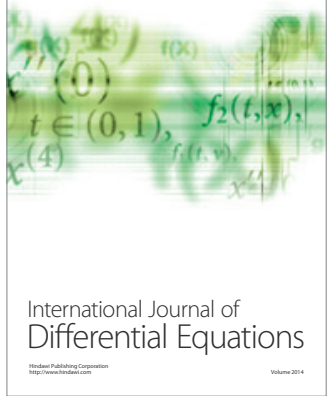
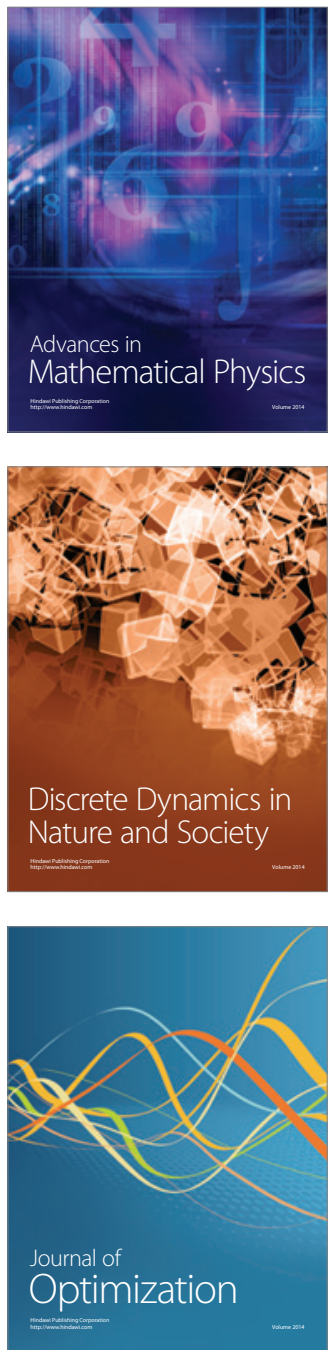